\title{
Complaints Against Family Physicians Submitted to Disciplinary Tribunals in the Netherlands: Lessons for Patient Safety
}

\author{
Sander Gaal, $M D^{1}$ \\ Chantal Hartman, $M D^{1}$ \\ Paul Giesen, $M D, P b D^{1}$ \\ Chris van Weel, $M D, P b D^{2}$ \\ Wim Verstappen, $M D, P b D^{1}$ \\ Michel Wensing, PbD, Habil ${ }^{1}$ \\ 'IQ healthcare, Radboud University \\ Nijmegen Medical Centre, Nijmegen, The \\ Netherlands \\ ${ }^{2}$ Department of Primary and Community \\ Care, Radboud University Nijmegen Medi- \\ cal Centre, Nijmegen, The Netherlands
}

\begin{abstract}
PURPOSE We analyzed the disciplinary law verdicts concerning family physicians, submitted to the Dutch disciplinary law system, to identify domains of high risk of harm for patients in family practice.

METHODS The Dutch disciplinary law system offers patients the opportunity to file complaints against physicians outside a legal malpractice system, without possibility of financial compensation in case of verdicts in which the physician was found to be at fault. We performed an analysis of 250 random disciplinary law verdicts on Dutch family physicians submitted to disciplinary tribunals and published between 2008 and 2010. Our analysis focused on clinical domains represented in the verdicts with serious permanent damage or death.
\end{abstract}

RESULTS Of the 74 complaints with a serious health outcome, $44.6 \%$ ( $n=33$ ) were related to a wrong diagnosis, $23.0 \%(n=17)$ to insufficient care, $8.1 \%$ $(n=6)$ to a wrong treatment, $8.1 \%(n=6)$ to a late arrival at a house visit, $5.4 \%$ $(n=4)$ to a late referral to the hospital, and $1.4 \%(n=1)$ to insufficient information given; $9.5 \%(n=7)$ consisted of other complaints. The wrong or late diagnosis-related cases mostly consisted of myocardial infarction and stroke (35.1\%) and malignancies (33.7\%). The family physician was disciplined as a result of 37 of these 74 complaints (50\%). Logistic regression analysis showed that a serious outcome was associated with a higher probability of disciplinary measures $(B=0.703 ; P=.02)$

CONCLUSIONS The disciplinary law system in the Netherlands differs fundamentally from a legal malpractice system. It can be used to learn from patients' complaints with a view on improving patient safety.

Ann Fam Med 2011;9:522-527. doi:10.1370/afm.1308.

\section{INTRODUCTION}

ince the publication of the landmark report To Err is Human in 1999, 1,2 patient safety has received considerable attention worldwide, although this attention has been focused mostly on hospital care. In countries with a strong primary health care system, such as the Netherlands, patients receive most of their medical care in family practice. In the Netherlands all citizens are registered with a family physician, who provides care for a full range of medical conditions across an extended period of time, including care of chronic and complex diseases. Improving patient safety is therefore essential in family practice settings. ${ }^{3,4}$ About $95 \%$ of all health problems are managed within the family practice setting. ${ }^{5,6}$ In 2002 , Dutch family physicians had a total of 61.4 million patient contacts. ${ }^{5} \mathrm{~A}$ recent Dutch patient record study of incidents related to patient safety in family practice showed that incidents do occur, but the study did not identify incidents with serious harm. ${ }^{7}$ Other studies of Dutch disciplinary law verdicts have found that preventable patient safety incidents with major 
consequences exist in family practice. ${ }^{8}$ The challenge is to identify and learn from such safety incidents in primary care, as their incidence is low. One potential approach is to focus on complaints against family physicians submitted to the Dutch disciplinary tribunals. The disciplinary law system in the Netherlands is uncommon; it is different from a malpractice system in that patients can file complaints against family physicians without resorting to lawsuits or insurance claims. Various methods can be used to identify patient safety incidents, but overlap between methods is limited., ${ }^{9,10}$ The aim of the present study was to describe and examine complaints against family physicians submitted to Dutch disciplinary tribunals with a view to improving patient safety.

\section{METHODS}

\section{Dutch Disciplinary System}

The system of disciplinary proceedings differs from country to country. In the Netherlands disciplinary law was introduced for physicians in 1928. The goal of disciplinary law is to guard and improve the quality of health care, to protect patients from incompetent and careless behavior, and to enhance public trust in the medical profession. ${ }^{11}$ Dutch disciplinary law differs from a malpractice system in that the patient does not receive financial compensation if the physician is found to be at fault. All family physicians are obligated by law to participate in the disciplinary system. ${ }^{12}$ The number of filed disciplinary law complaints has increased every year. In 2009 there were 1,496 complaints, of which 237 were related to family physicians. ${ }^{11}$

Every family practice is also obligated to have a system for patients to file complaints, which are then taken care of within the practice. A third option is to file a malpractice claim at the civil courts in the Netherlands. To our knowledge, however, no detailed information is currently available for the number of complaints or malpractice claims that are filed yearly against family physicians. Although it is possible to file complaints using more than one system, we focused only on complaints filed at the Dutch disciplinary tribunals.

There are 5 disciplinary law tribunals in the Netherlands where anyone who has been in the care of a physician (either as a patient or as a patient's relative) can file a complaint. In some cases the Dutch health care inspectorate can also file a complaint. The complaints must be addressed to an individual physician (that is, not to a hospital or family practice facility) and filed within 10 years after the act or omission. The tribunal has 5 members: 2 lawyers and 3 members from the same discipline as the physician under judgment.
The tribunal reviews the complaint according to the standard given in Dutch law: any act or omission by a physician directed at a patient, or the relative(s) directly involved in a patient's care or support, that went contrary to what is considered appropriate by the medical profession. After a tribunal verdict, it is possible to file a high appeal at a central disciplinary tribunal.

Before a formal meeting, the disciplinary tribunal researches the nature of the complaint. If a complaint appears to be justified, a copy of the complaint is sent to the defendant with a request for a written response. The plaintiff can file a second statement in reply to the defendant's response. If necessary, the disciplinary tribunal can ask for additional information from, for example, other health care workers involved. After this information is collected, the tribunal asks the plaintiff and defendant for a private hearing. This hearing is not mandatory, but it can be used to seek a resolution between the plaintiff and defendant. If the case is not resolved, the complaint is submitted to the disciplinary tribunal for further review. The disciplinary tribunal reads the written statements, at which time either they can find the complaint inadmissible and reject it, or they can accept it for a formal review. If the tribunal rejects the complaint, this verdict is always described in a motivated report.

If the tribunal accepts the complaint, a public hearing takes place. At the hearing both parties have an opportunity to explain their positions further. The tribunal can request additional information from the defendant or the plaintiff. If the parties have experts or witnesses, they are also heard. The tribunal then passes a written judgment and publishes the verdicts anonymously online. Each week a verdict of interest is published anonymously in a medical journal with a commentary by the Dutch health care inspectorate. ${ }^{14}$

The complete process, from filing a complaint to the judgment, usually takes between 1 and 2 years. ${ }^{12,13}$ If the physician is found to be at fault, a number of disciplinary measures can be imposed, ranging from a warning or a reprimand to a fine (up to a maximum of $€ 4,500$, which is paid to the state) or temporary or permanent suspension from practice. The more severe sanctions are rarely imposed.

\section{Study Design and Sample}

Our study was a retrospective analysis of the disciplinary law verdicts in family practice published anonymously on the Internet (http://www.tuchtrecht .nl, and since January 1, 2010, http://www.tuchtcollegegezondheidszorg.nl). These extensive reports, which contain full descriptions of the complaints and the judgments (or acquittal), as well as the underlying considerations of the verdict, provided the data for the 
study. By searching these 2 Web sites, using the search term Huisarts (family physician), we were able to collect 250 most recently published disciplinary law verdicts for family physicians. We decided on 250 cases by consensus, as we anticipated that we could analyze this number of cases within the time frame of the study, and 250 verdicts would present a sufficient variety of medical errors and sanctions. The verdicts were dated from July 2008 until October 2010. To avoid duplicate verdicts, only original verdicts were collected (not appeals to the central disciplinary law college). The Medical Ethics Committee of the Radboud University Nijmegen Medical Centre approved this study.

\section{Data Extraction and Analysis}

The published reports of the disciplinary law verdicts were read and descriptively analyzed by 2 physicians (C.H., S.G.), who abstracted the following information: classification of complaint, the diagnosis when applicable, the health outcome for the patient, and the verdict given by the tribunal. We used the classification types described in the disciplinary law verdicts annual report, and when in doubt about the classification, consensus was sought and reached easily. We used the following definition for a patient safety incident: "an unintended event during the care process that resulted, could have resulted, or still might result in harm to the patient." If a patient safety incident (avoidable error) occurred, a verdict resulted in disciplinary measures by the tribunal, because the family physician involved performed an action below the professional standard. Not all avoidable errors resulted in health consequences for the patient, however. We paid special attention to the complaints with serious health outcomes and used logistic regression models to find significant differences between the type of complaint, the health outcomes, and the percentage of negligence verdicts. For example, we checked the relation between the severity of the health outcome and the verdict.

\section{RESULTS}

Our study included 250 disciplinary law verdicts of family physicians from approximately a 2 -year period. The verdicts were spread equally across the 5 different regional tribunals; 125 complaints (50.0\%) had been filed by the patient, $108(43.2 \%)$ by a family member, and $3(1.2 \%)$ by the health care inspectorate. In 14 cases $(5.6 \%)$ the type of filer could not be retrieved. Of the complaints 172 (68.8\%) resulted from medical care during the daytime and 45 (18.0\%) from after-hours care (evenings, nights, and/or weekends). There were 14 (5.6\%) cases filed against family physicians who were employed elsewhere (eg, military base or prison) $)_{i}$ in 19 cases $(7.6 \%)$ the location where the patient had been treated could not be retrieved. A total of $28(11.2 \%)$ complaints were rejected or found not applicable by the tribunal at the time of filing and did not result in a hearing.

\section{Type of Complaints}

Sixty complaints $(24.0 \%)$ were related to a wrong diagnosis, $54(21.6 \%)$ to insufficient medical care, $23(9.2 \%)$ to wrong treatment, $18(7.2 \%)$ to a too late referral, $15(6.0 \%)$ to an incorrect statement or declaration, 14 $(5.6 \%)$ to violation of privacy, $14(5.6 \%)$ to not showing up or showing up too late at a house visit, $6(2.4 \%)$ to provision of insufficient information, $5(2.0 \%)$ to impolite behavior, and $2(0.8 \%)$ to inappropriate patient contact 1 complaint $(0.4 \%)$ was related to the billing for the treatment, and 19 (7.6\%) were for other reasons. For another 19 cases (7.6\%), it was impossible to identify the type of complaints (Table 1 ).

\section{Consequences for Patients}

In 71 cases $(28.4 \%)$ there were no health consequences for the patient involved, in 37 cases $(14.8 \%)$ there was small harm, and in 46 cases $(18.4 \%)$ there was medium harm. In 25 cases (10.0\%), however, there was severe harm, and in 49 cases $(19.6 \%)$ the patient had died, for a total of 74 cases for which there were serious outcomes (severe harm or death). In 22 cases (8.8\%) the health consequences remained unknown.

\section{Verdicts}

One hundred thirty-four cases (53.6\%) were suspended, 18 cases $(7.2 \%)$ were declared not applicable, 9 cases $(3.6 \%)$ were withdrawn, and 1 case $(0.4 \%)$ was not further pursued by the plaintiff. In 88 cases $(35.2 \%)$ the family physician was disciplined. Of the 88 negligence verdicts, 69 resulted in a warning, 11 in a reprimand, and 2 in a temporary suspension from practice. In 6 cases no disciplinary measure was given. All inappropriate patient contacts (100\%), violations of privacy $(64.3 \%)$, and an incorrect statement of declaration $(53.3 \%)$ resulted in disciplinary measures. Some of these categories, however, contained only a few complaints (Table 1). Logistic regression analysis showed that a serious outcome was associated with a higher probability of disciplinary measures $(B=0.703, P=.02)$

\section{Complaints With Serious Health Outcomes}

Of the 74 complaints with a serious health outcome, $44.6 \%(n=33)$ were related to a wrong diagnosis, $23.0 \%(n=17)$ to insufficient care, $8.1 \%(n=6)$ to a wrong treatment, $8.1 \%(\mathrm{n}=6)$ to a too late arrival at a house visit, $5.4 \%(\mathrm{n}=4)$ to a late referral to the hospital, and $1.4 \%(\mathrm{n}=1)$ to insufficient information given. Other 
Table 1. Description and Number of Complaints $(\mathrm{N}=250)$

\begin{tabular}{|c|c|c|c|c|}
\hline Type and Example of Complaint & Complaints & $\begin{array}{l}\text { Complaints } \\
\text { With } \\
\text { Physician } \\
\text { at Fault }\end{array}$ & $\begin{array}{l}\text { Complaints } \\
\text { With Serious } \\
\text { Health } \\
\text { Outcomes }\end{array}$ & $\begin{array}{l}\text { Complaints With } \\
\text { Serious Health } \\
\text { Outcomes and } \\
\text { Physician at Fault }\end{array}$ \\
\hline $\begin{array}{l}\text { Wrong diagnosis: allowing cycling, when a hip fracture was diag- } \\
\text { nosed later; diagnosing influenza in a patient with meningitis }\end{array}$ & 60 & 27 & 33 & 18 \\
\hline $\begin{array}{l}\text { Insufficient medical care: family physician diagnoses myocar- } \\
\text { dial infarction but does not stay with patient until ambulance } \\
\text { arrives, and patient dies of cardiac arrest before ambulance } \\
\text { arrives. No referral to a urologist in a male patient with recur- } \\
\text { ring urinary infections }\end{array}$ & 54 & 20 & 17 & 11 \\
\hline $\begin{array}{l}\text { Wrong treatment: giving amoxicillin to a patient with known } \\
\text { allergy; wrong type of lithium }\end{array}$ & 23 & 6 & 6 & 2 \\
\hline $\begin{array}{l}\text { Referral too late: missing of a malignancy (metastatic) in a patient } \\
\text { with lower back pain; missing of a breast carcinoma }\end{array}$ & 18 & 4 & 4 & 3 \\
\hline $\begin{array}{l}\text { Incorrect statement or declaration: family physician gives an } \\
\text { incorrect statement to the police about violence within a fam- } \\
\text { ily; family physician gives incorrect information about the hus- } \\
\text { band in a child abuse case }\end{array}$ & 15 & 8 & 0 & 0 \\
\hline $\begin{array}{l}\text { Violation of privacy: family physician notes down medical } \\
\text { information about patient in letter to her ex-husband; family } \\
\text { physician gives the medical record to a family member without } \\
\text { permission }\end{array}$ & 14 & 9 & 0 & 0 \\
\hline $\begin{array}{l}\text { Not showing up, or too late at a house visit: family physician } \\
\text { refuses a house visit for a patient with (as later shown) a stroke; } \\
\text { family physician refuses a house visit because patient lives too } \\
\text { far away }\end{array}$ & 14 & 2 & 6 & 1 \\
\hline $\begin{array}{l}\text { Insufficient information: eg, family physician did not give infor- } \\
\text { mation about side effects of corticosteroid; family physician } \\
\text { refuses to talk to a patient }\end{array}$ & 6 & 3 & 1 & 1 \\
\hline $\begin{array}{l}\text { Impolite behavior: family physician refuses to lift fallen patient, fire } \\
\text { department had to come; family physician shouts at a patient }\end{array}$ & 5 & 2 & 0 & 0 \\
\hline $\begin{array}{l}\text { Inappropriate contact with patient: sexual relationship with a } \\
\text { patient }\end{array}$ & 2 & 2 & 0 & 0 \\
\hline Wrong billing: patient found billing too high & 1 & 0 & 0 & 0 \\
\hline Other & 19 & 5 & 7 & 1 \\
\hline Impossible to identify the type of complaints & 19 & 0 & 0 & 0 \\
\hline Total & 250 & 88 & 74 & 37 \\
\hline
\end{tabular}

complaints accounted for $9.5 \%(n=7)$. Analysis showed that the diagnosis-related cases consisted mostly of cardiovascular diseases (35.1\%) and malignancies (33.7\%). Logistic regression analysis showed that wrong treatment $(B=-1.181 ; P<.03)$ and insufficient treatment $(\mathrm{B}=-0.978 ; P<.01)$ had a lower probability for serious harm when compared with a wrong diagnosis.

\section{DISCUSSION}

\section{Main Findings}

In our quest to improve the medical care we provide, our mistakes can teach us as much as our successes.

One would imagine, therefore, that data from malpractice claims and disciplinary proceedings would prove to be easy pickings. Our findings must be interpreted within the context of the approximately 60 million contacts between patients and family physicians every year in the Netherlands. It is difficult to draw conclusions from a small number of verdicts. This study shows that disciplinary law verdicts for family physi- cians cover a wide range of complaints, with wrong diagnosis and insufficient medical care being the largest categories. In 74 cases a serious health outcome occurred, of which 37 were assessed as avoidable harm by the disciplinary tribunals. The most serious health outcomes, permanent disability or death, were related to a wrong diagnosis.

\section{Differences Between the Dutch Disciplinary Tribunal System and the US Malpractice System}

The Dutch disciplinary system has no potential financial benefit for patients involved-the main objectives are to learn from mistakes and improve the quality of health care. In comparison, the principal objectives of the US medical malpractice system are to compensate patients injured through clinician negligence and to deter future negligent actions. The Dutch disciplinary system offers an opportunity to file complaints against family physicians without the burden of large financial penalties for the health care system involved. In addition to the disciplinary tribunal system, a party can file 
a negligence claim in civil court; however, the number of these procedures involving family physicians is not publicly known. Research suggests that for Dutch hospitals there are few claims when compared with the hospitals in United States, and the number of claims in the Netherlands did not increase significantly during the last decades. ${ }^{15}$

\section{Verdicts}

From a patient safety perspective, the verdicts with serious health outcomes are of particular interest to the tribunals, because in these cases the family physician deviated in his or her performance from clinical guidelines (a preventable patient safety incident occurred), which resulted in serious harm. Most of the negligence verdicts with serious health outcomes in our study were diagnosis related. Most diagnostic errors resulted in problems of inadequate history taking and physical examination. In general, verdicts with serious health outcomes were related to an acute and life-threatening illness (eg, myocardial infarction or stroke). Incidents related to inappropriate patient contacts, violation of privacy, or a wrong statement or declaration did not have serious health consequences for patients.

Missing a diagnosis does not directly result in a disciplinary law verdict, so when conducting an adequate physical examination, missing a diagnosis is often not cause for disciplinary action. ${ }^{11}$ Because of the characteristics of a family practice setting, the self-limiting nature of most diseases, and the accepted method of watchful waiting, many tests have a low predictive value. The essential purpose of the physical examination is to filter out life-threatening and serious diseases. For example, a family physician sees many patients with chest pain. It is impossible to refer every patient to the hospital for a cardiac checkup. The family physician has to determine which chest pain is of cardiac origin based on limited diagnostic features. With hindsight it may be sometimes easy to recognize the correct diagnosis, but such is not the case in daily care. ${ }^{16}$ Professional behavior primarily includes a thorough physical examination, weighing the signs and symptoms against the possibility of a serious disease. ${ }^{12}$ The tribunals in the Netherlands do not expect physicians to establish correct diagnoses for all their patients, but they do expect the use of a recommended physical examination and diagnostic tests whenever necessary. ${ }^{12}$

\section{Comparison With Previous Research}

Results of a study of disciplinary law verdicts on Dutch out-of-hours care were similar to those of our study: most negligence verdicts were related to a late or missed diagnosis and to an error in triage. ${ }^{17}$ Our study found fewer complaints of triage errors. Although not directly comparable, because most studies researched negligence claims, a 1998 study from California showed a different distribution of types of complaints. In the California study, there were more complaints of alcohol or drug abuse by health professionals, inappropriate patient contacts, and fraud. ${ }^{18}$ A negligence claims study involving British National Health System, however, also showed that the most common error in family practice was failure or delay in diagnosis. ${ }^{19}$ A few large studies have been conducted regarding malpractice claims. One study of 50,000 primary care claims showed negligence in $23 \%$ of the cases. The largest category was, again, an error in diagnosis. This study reported the same categories for which most of the complaints had been filed: myocardial infarction and malignancies. ${ }^{20}$ Comparison with disciplinary law verdicts and negligence claims is difficult because of the differences in systems. ${ }^{21}$

\section{Lessons for Patient Safety}

In a large-scale medical record review in the Netherlands, we found a 1 -year prevalence of $5.8 \%$ for patient safety incidents with consequences affecting the involved patient. ${ }^{7}$ These incidents consisted mostly of minor health consequences, and no incidents related to death were found. Analysis of disciplinary verdicts may be more appropriate for identifying and analyzing incidents with serious health outcomes. The representativeness of disciplinary verdicts is unknown, however, as physicians were found to be at fault in only 37 cases with serious outcomes from approximately 120 million contacts with 10 million patients. On the one hand, the disciplinary verdicts reconfirm the importance of timely and comprehensive diagnostic procedures, particularly for patients with suspected life-threatening conditions. The threshold for hospital admission in the Netherlands is probably higher compared with countries that have less well-developed primary care systems. This higher threshold could constitute a potential safety risk, as the family physician must make clinical decisions with the aid of only a few diagnostic possibilities (eg, no radiographs, frequently no electrocardiograms). Potentially the development and implementation of quick tests, and additional test possibilities in family practice can help to improve diagnostic performance in primary care. On the other hand, risks cannot be avoided completely in real life, and the total number of complaints submitted to disciplinary tribunals was extremely low. More emphasis on patient safety also has its price in terms of undesirable medicalization and higher financial costs. Thus, the challenge is to find a balance between patient safety by performing additional procedures and a legitimate trust in the favorable prognosis of many health problems encountered in primary care. 


\section{Limitations}

Every available method of researching patient safety incidents has its difficulties. The literature shows little overlap in the different methods used to document the prevalence of patient safety incidents., ${ }^{9,10,22}$ Prevalence of incidents cannot be calculated from this study because of the relatively small sample of disciplinary law verdicts and the few complaints researched. Currently the medical record review offers the best means of assessing the prevalence of patient safety incidents. ${ }^{23}$ The disciplinary law verdicts posted anonymously on the Internet provided considerable information on the verdict and the reasons for it ${ }_{i}$ however, no other information, such as demographic characteristics of the family physicians (eg, sex, age, or practice location) or patients, could be retrieved. Hindsight bias could have occurred when reviewing these verdicts. Problems with communication played a part in many complaints. It is highly likely that many more serious patient safety incidents do occur, but they never lead to a disciplinary law complaint, a potential bias. Accordingly, this study cannot be used to measure the prevalence of incidents.

In this study, serious patient safety incidents were found that had not been detected by other methods, such as large-scale medical record review or incident reporting. ${ }^{7}$ The Dutch disciplinary system can be a useful system to file and learn from complaints, apart from a negligence claim system. It seems logical to include disciplinary law verdicts into studies to search and learn from patient safety incidents, because serious preventable incidents are described. Most incidents with serious health consequences were diagnosis related; therefore, more attention to diagnosis in family practice in patient safety programs could be useful.

To read or post commentaries in response to this article, see it online at http://www.annfammed.org/content/9/6/522.

Key words: Family practice; patient safety; patient advocacy; disciplinary law verdicts; medical errors; medical jurisprudence

Submitted March 16, 2011; submitted, revised June 9, 2011; accepted June 23, 2011.

\section{References}

1. Institute of Medicine. Committee on Quality of Health Care in America. To Err Is Human: Building a Safer Health System. Washington, DC: National Academies Press; 2000.

2. Stelfox HT, Palmisani S, Scurlock C, Orav EJ, Bates DW. The "To Err is Human" report and the patient safety literature. Qual Saf Health Care. 2006;15(3):174-178.

3. Starfield B, Shi L, Macinko J. Contribution of primary care to health systems and health. Milbank Q. 2005;83(3):457-502.

4. Gandhi TK, Lee TH. Patient safety beyond the hospital. N Engl J Med. 2010;363(11):1001-1003.
5. Ministry of Health Welfare and Sport. Primary Health Care in the Netherlands. International Publication Series Health Welfare and Sport no 20. 2005.

6. Fournier AM. Primary care remuneration-a simple fix. N Engl J Med. 2009;361(10):e102.

7. Gaal S, Verstappen W, Wolters R, Lankveld H, van Weel C, Wensing $M$. Prevalence and consequences of patient safety incidents in general practice in the Netherlands: a retrospective medical record review study. Implement Sci. 2011;6(1):37.

8. van der Wal G. Medical disciplinary jurisprudence in The Netherlands; a 10-year review. Ned Tijdschr Geneeskd. 1996;140(52): 2640-2644

9. Wetzels R, Wolters R, van Weel C, Wensing M. Mix of methods is needed to identify adverse events in general practice: a prospective observational study. BMC Fam Pract. 2008;9:35.

10. Christiaans-Dingelhoff I, Smits M, Zwaan L, Lubberding S, van der Wal G, Wagner C. To what extent are adverse events found in patient records reported by patients and healthcare professionals via complaints, claims and incident reports? BMC Health Serv Res. 2011;11(1):49

11. Jaarverslag Tuchtcolleges voor de Gezondheidszorg 2009. 2010. Den Haag. http://www.tuchtcollege-gezondheidszorg.nl/lmages /Gezamenlijk\%20jaarverslag\%202010_tcm11-25504.pdf.

12. Stolper E, Legemaate J, Dinant GJ. How do disciplinary tribunals evaluate the "gut feelings" of doctors? An analysis of Dutch tribunal decisions, 2000-2008. J Law Med. 2010;18(1):68-75.

13. Cuperus-Bosma JM, Hout FA, Hubben JH, van der Wal G. Views of physicians, disciplinary board members and practicing lawyers on the new statutory disciplinary system for health care in The Netherlands. Health Policy. 2006;77(2):202-211.

14. Medisch contact [Web site]. http://medischcontact.artsennet.nl/ tuchtzaken.htm. Accessed May 25, 2011.

15. Hubben JH, Christiaans I. No spectacular rise in claims for medical

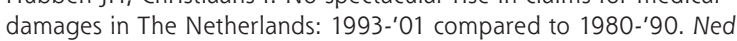
Tijdschr Geneeskd. 2004;148(25):1250-1255.

16. Fischhoff B. Hindsight not equal to foresight: the effect of outcome knowledge on judgment under uncertainty. 1975. Qual Saf Health Care. 2003;12(4):304-311, discussion 311-312.

17. Blaauw $C$, Jongerius $P$, Hubben J. De huisartsenpost in de tuchtrechtspraak 1997-2007; enkele leerpunten voor de praktijk. [Outof-hours family physician medical care in disciplinary law verdicts 1997-2007; some lessons for the practice]. Bijblijven. 2010;9:52-57.

18. Morrison J, Wickersham P. Physicians disciplined by a state medical board. JAMA. 1998;279(23):1889-1893.

19. Esmail A. Patient safety - what claims against the NHS can teach us. J Health Serv Res Policy. 2010;15(Suppl 1):33-36.

20. Phillips RL Jr, Bartholomew LA, Dovey SM, Fryer GE Jr, Miyoshi TJ, Green LA. Learning from malpractice claims about negligent, adverse events in primary care in the United States. Qual Saf Health Care. 2004;13(2):121-126.

21. Vincent C, Davy C, Esmail A, et al. Learning from litigation. The role of claims analysis in patient safety. J Eval Clin Pract. 2006; 12(6):665-674.

22. Olsen S, Neale G, Schwab K, et al. Hospital staff should use more than one method to detect adverse events and potential adverse events: incident reporting, pharmacist surveillance and local realtime record review may all have a place. Qual Saf Health Care. 2007;16(1):40-44.

23. Lilford RJ, Mohammed MA, Braunholtz D, Hofer TP. The measurement of active errors: methodological issues. Qual Saf Health Care. 2003;12(Suppl 2):ii8-ii12. 